\title{
Quality of oral surgery referrals and how to improve them
}

\section{Mikael Björkeborn' \\ Henrik Nilsson ${ }^{2}$ \\ Jonas Anderud'}

'Department of Oral and Maxillofacial Surgery, Halmstad Hospital, Halmstad, Sweden; ${ }^{2}$ Department of Oral and Maxillofacial Surgery, Växjö Hospital, Växjö, Sweden
Correspondence: Mikael Björkeborn Department of Oral and Maxillofacial Surgery, Halmstad Hospital, Lasarettsvägen, 30233 Halmstad, Sweden Email m.bjorkeborn@gmail.com
This article was published in the following Dove Press journal:

Clinical, Cosmetic and Investigational Dentistry

I5 November 2017

Number of times this article has been viewed

Aim: To assess the quality of routine oral surgery referrals received at Halmstad Hospital and Växjö Hospital and to emphasize areas for improvement.

Method: A retrospective study was performed on all routine oral surgery referrals received between 2014 and 2015 at both Halmstad Hospital and Växjö Hospital. A total of 1,891 referral letters were assessed for their quality against a predetermined checklist of basic requirements of a satisfactory referral. The referrals were also categorized according to if it was sent by a male, female, private dental service, or the Swedish Public Dental Health service.

Results: A diagnosis was missing in $30 \%$ of all referrals. Radiographs and information about previous radiographic examinations were not included in $10 \%$ of the referrals. Of those referrals that included radiographs, only around half were deemed adequate for diagnostic purposes. The presenting complaint was missing in $40 \%$ of all referrals. Current medical history was absent in $40 \%$ and current medication was omitted in $60 \%$ of the referrals. Information about tobacco use was only included in $10 \%$ of all referrals. Overall, female referrers performed better than male colleagues. Private referrals more regularly included information about diagnosis, previous treatment, and current medication. On the other hand, referrals from the public dental health service more frequently included radiographs, tobacco use, and current medical history.

Conclusion: There is plenty of room for improving the standards of oral surgery referrals. We suggest that future electronic referral systems should only allow for submission once all of the essential information has been considered.

Keywords: clinical audit, referral quality, oral surgery referrals

\section{Introduction}

In a normal working day, it is common for most dentists to refer to another dentist or specialist who would be able to carry out the treatment to a higher standard and more effectively. ${ }^{1}$ It is paramount that a dentist is aware of his own limitations and is able to discern when a referral is required. In fact, referring patients between health care providers is part of a complete quality health care approach. However, several published audits and studies have shown that the standards of oral surgery referrals are universally poor. ${ }^{2-6}$ In this study, we performed a retrospective analysis of all routine oral surgery referrals received at two different oral surgery departments in Sweden.

Good quality dental referrals should contain all the necessary information for ensuring efficient and safe treatment without delaying diagnosis and treatment. ${ }^{7}$ In addition, the workflow process is improved as appointments and additional tests can be avoided. ${ }^{8}$ This eliminates unnecessary exposure to ionizing radiation, eliminates time wastage, reduces cost, and improves patient experience. ${ }^{9}{ }^{10}$ Incomplete referrals 
might lead to increased patient frustration, anxiety, and dissatisfaction with the health care system. Moreover, referrals are important medicolegal documents and often the main method of communicating confidential information between health care professionals. ${ }^{1,11}$

There are no general national guidelines for dental referrals in Sweden such as the ones published by the ADA. ${ }^{12}$ There are, however, legal requirements such as the SOSFS 2004:11 statues by the Swedish National Board of Health and Welfare, which defines who is responsible for issuing the referral and what type of routines are necessary. ${ }^{13}$ It is therefore important that communication is efficient and contains appropriate information that avoids unnecessary correspondence for clarification purposes. This is especially important for some oral surgery departments that aspire toward offering patients a single-visit approach for routine oral surgery procedures.

\section{Aims and methods}

The aim of this study was to assess the quality of routine oral surgery referrals received at Halmstad Hospital and Växjö Hospital and to emphasize areas for improvement. The study protocol did not require ethical approval from the Region Halland Institutional Review Board. This was according to the hospital protocol. All patient data was anonymized. The primary purpose of this study was to allow quality improvement to take place in order to improve patient care.

All of the referrals received during the year of 2014 regarding apicectomy, wisdom tooth surgery, and implant surgery were sampled. The oral surgery referrals came from the Swedish Public Dental Health (PDH), private health care providers, specialty clinics, and dental hospitals. Self-referrals and referrals from other medical health care providers were excluded from the study due to their small sample size. The total number of audited referrals was 1,891 . The county of Halland accounted for 1,074 of these, whereas the county of Kronoberg amounted to 817 of the total number of referrals. All referrals were reviewed by two observers.

The following factors were recorded: patient data, referrer details, patient address, diagnosis, reason for referring, radiographs, adequate radiographs, presenting complaint, smoking habits, previous treatment, disorders, medication, allergy, medical history, type of surgery (apical surgery, wisdom tooth surgery, or implant surgery), gender of the referrer, and if the referrer works in the Swedish Public Dental Care, private health care, or in a dental specialty clinic.

The following computer programs were used for reviewing the clinical records and radiographs: T4 (Carestream
Dental AB, Stockholm, Sweden), VAS Plus (Norrbotten County Council, Sweden), Arion (Pro Curis AB, Lund, Sweden), and PACs (GE Healthcare, Barrington, IL, USA).

All 1891 referrals were scored against the predetermined checklist. As for the radiographs, observations were made whether any adequate analog or digital films were attached or if additional imaging was required. SPSS version 22.0 (IBM, Armonk, NY, USA) was used for statistical analysis. Analysis of the data was made through Pearson's $\chi^{2}$ tests. The level of statistical significance was set at the 0.05 level.

\section{Results}

Figure 1 illustrates the outcome of all referrals included in the study: $68.7 \%$ contained a diagnosis and $98.9 \%$ of the referrals included a reason for referring. In terms of radiographs, $90.2 \%$ of referrals included some form of an attached radiograph. On the other hand, adequate radiographs were only found in $46.6 \%$ of the cases. Regarding symptoms, only $62.1 \%$ of referrals included information. Whether the patient was using tobacco or not was only included in $9.9 \%$ of the cases. Previously completed dental treatment was mentioned in $36.4 \%$ of all cases. Disorders appeared in $59.7 \%$, medication in $39.9 \%$, and allergies in $28.2 \%$.

Figure 2 shows the result of referrals when comparing private and public dentistry. PDH referrals included radiographs more often than private dentists, at $92.6 \%$ compared to $84.8 \%$. This was statistically significant $(p<0.0001)$. PDH dentists were also more prone to include information regarding tobacco use $(11.4 \%)$ compared to private practitioners $(6.5 \%)(p<0.001)$. With regard to inclusion of information about medication, the private practitioners tended to include this information more often $(46.5 \%)$ compared to $\mathrm{PDH}$ dentists $(37.0 \%)(p<0.0001)$. Allergies where more often included by PDH dentists $(29.6 \%)$ than private dentists $(25.0 \%)(p<0.043)$.

Figure 3 shows a comparison of referrals between female and male dentists. X-ray pictures attached to the referral were more often included by female referrers $(91.7 \%)$ than male $(88.1 \%)(p<0.010)$. The same was seen with regard to disorders $(p<0.0001)$, medication $(p<0.003)$, and allergy $(p<0.0001)$, with female referrers having higher tendency of including information than male referrers. There was also a tendency that female referrers more frequently included information about tobacco use $(10.9 \%)$ than male referrers $(8.4 \%)(p<0.073)$.

Finally, there were statistically significant differences in the reason for referring. Referrals for wisdom teeth extraction included diagnosis in $58.5 \%$ of the cases compared to 


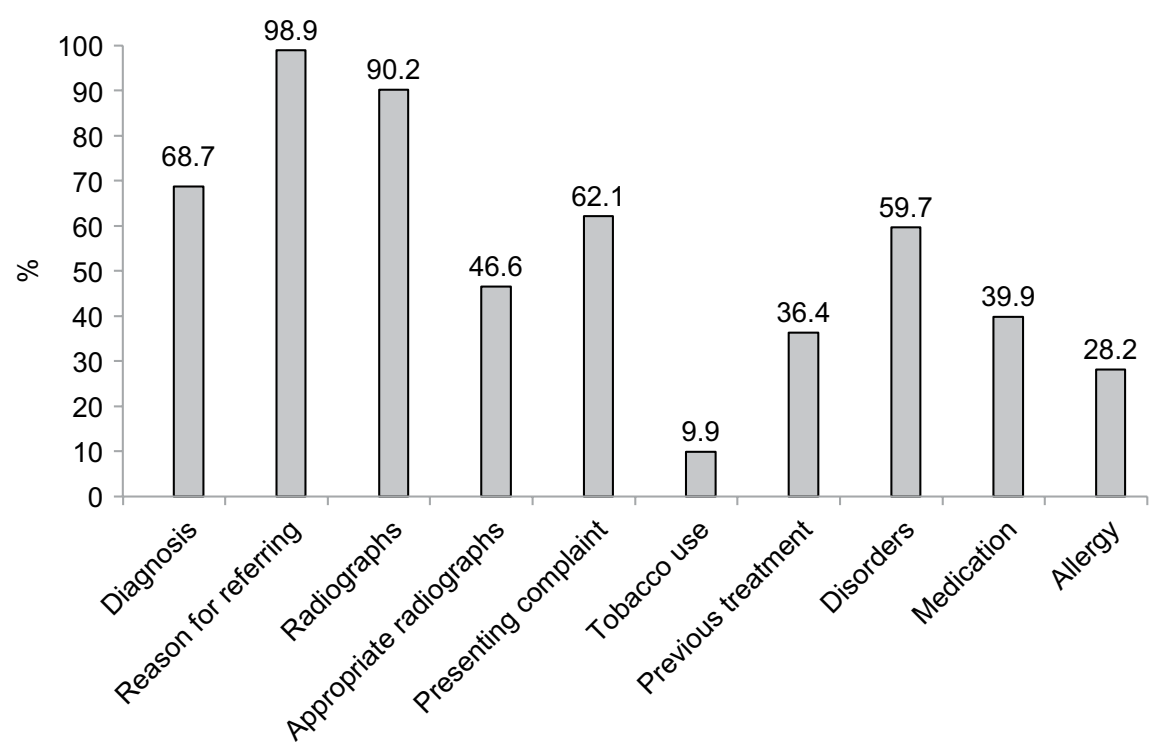

Figure I Results for routine oral surgery referrals audited between 2014 and 2015.

Note: $n=|, 89|$.

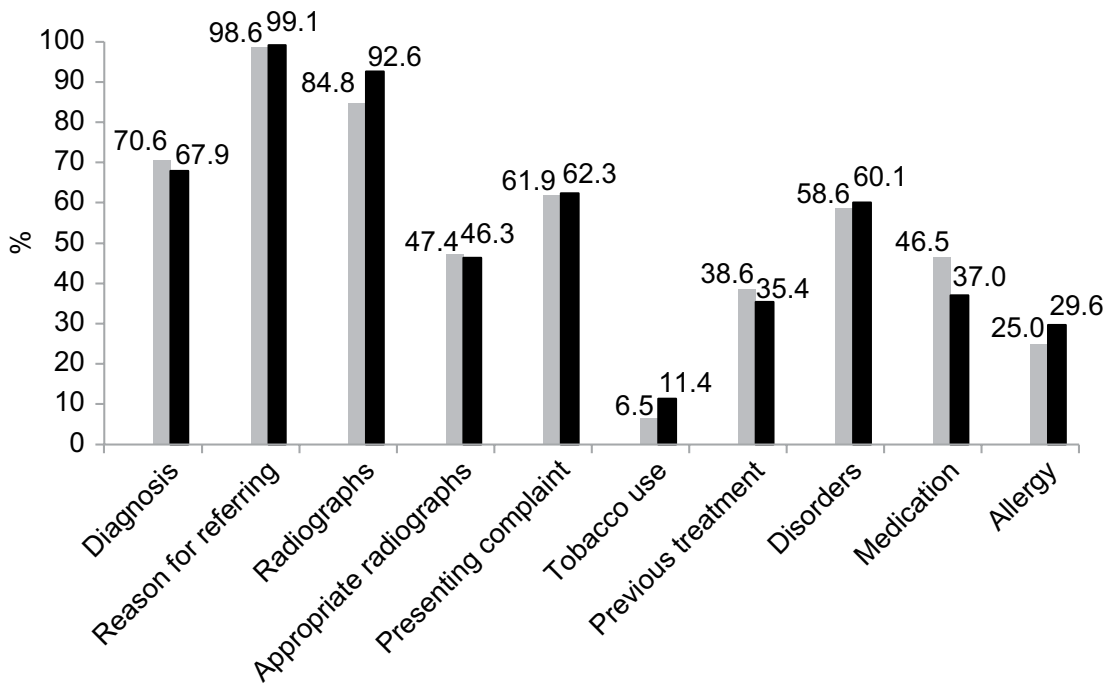

Figure 2 Results for routine oral surgery referrals.

Notes: Comparison between private practitioners and PDH practitioners. Gray column = private practitioners. Black column $=$ PDH. $\mathrm{n}=\mathrm{I}, 89 \mathrm{I}$.

Abbreviation: PDH, Public Dental Health.

$71.8 \%$ for apicectomy referrals $(p<0.001)$. Moreover, there were statistical differences regarding adequate radiographs, as wisdom teeth referrals included adequate radiographs in only $44.4 \%$ of the referrals compared to $73.2 \%$ for apicectomy referrals $(p<0.001)$. Similarly, previous treatment was more often included in apicectomy referrals at $57.5 \%$ versus $24.4 \%$ for wisdom teeth referrals $(p<0.001)$. Medication was also included in $45.7 \%$ of apicectomy referrals versus $36.2 \%$ for wisdom teeth referrals $(p<0.001)$.

\section{Discussion}

Overall, the quality of referrals was unsatisfactory, despite the generous inclusion criteria. Some referrals were so poorly written that they posed a threat to patient safety. Perhaps many of these referrals should not have been sent in the first place. On the other hand, the results also indicate that many referrers manage to submit referrals with satisfactory information regarding the reason for referring. This is perhaps straightforward as a referral is in essence a request for treatment 


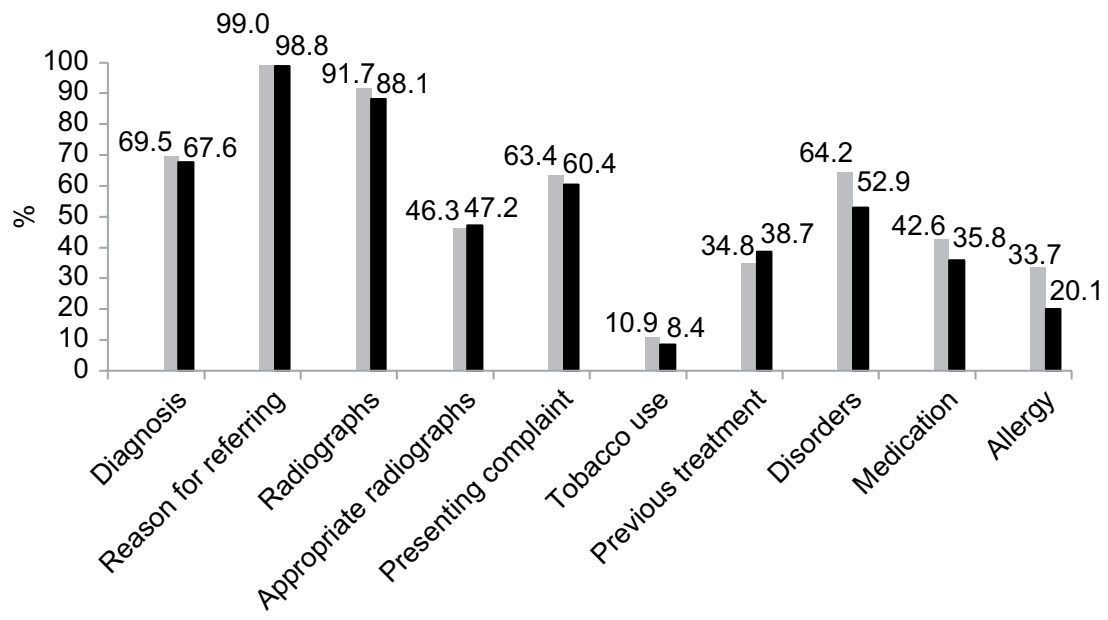

Figure 3 Results for routine oral surgery referrals.

Notes: Comparison between female versus male referrers. Gray $=$ female, Black $=$ male. $n=1,891$.

and/or diagnosing. However, diagnosis was less frequently reported than the reason for referring. This worrying fact is similar to what other authors have concluded in their studies. ${ }^{46,8}$ Symptoms were even less frequently reported than diagnosis, maybe because most dentists fail to record them accurately in their own clinical notes.

Preoperative radiographs are a necessity for most elective dentoalveolar surgical procedures and in order to appropriately triage the referral. Previous studies have concluded that referrals for wisdom teeth surgery frequently lack appropriate radiographs. ${ }^{14,15}$ Radiographic assessment is necessary for anticipating the difficulty and planning the surgical approach. Appropriate radiographs sometimes require a panoramic radiograph for wisdom teeth and implant surgery for instance in order to assess proximity to nerves, sinuses, root anatomy, and bone height. As most dental professionals aim to adhere to the As Low As Reasonably Achievable principle, repeated exposure is undesirable. One solution would be to demand a panoramic radiograph prior to the referral being sent. Unfortunately, there are no published Swedish guidelines for standards of care regarding what type of dental radiographs are indicated for a particular oral surgery procedure. For periapical surgery, plain-film radiographs would be enough for the initial assessment, as a periapical infection could easily be detected with this technique. Perhaps many clinicians are under the perception that appropriate radiographs should be ordered by the specialist who will undertake the procedure. Many referrers may feel apprehensive about prescribing radiographic examinations for procedures that they do not intend to carry out themselves. ${ }^{16}$ Perhaps this explains why periapical surgery referrals more often contained appropriate radiographs, as plain-film radiographs are usually sufficient for the initial assessment. In addition to radiographs, information concerning tobacco consumption was also poorly recorded. In this study, very few referrers added information about smoking and tobacco use. Other surgical specialties (ie, orthopedic surgery) in some hospitals in Sweden do not operate on patients who are tobacco users. Swedish dental professionals are encouraged to offer smoking cessation advice to all patients who smoke tobacco.

Unfortunately, dentist often fail to view their patients with a goal of holistic approach. Even though the inclusion criteria in this study were extremely generous, the authors of this paper are of the opinion that allergies must be mentioned in all referral letters, even if the patient has none. This is vital to avoid misunderstandings and the potentially fatal consequences that could arise as a result. Similarly, for patients taking anticoagulation medication, an up-to-date list of medications is critical. For instance, patients taking antiresorptive bone drugs such as bisphosphonate require substantially more time and planning prior to surgery. Although a controversial issue, a small group of patients might also qualify for antibiotic cover prior to dentoalveolar surgery.

As most oral surgery departments in Sweden strive toward delivering a one-stop service for routine oral surgery, complete referrals allow for appropriate presurgical planning and avoiding delays. In other branches of medicine, direct listing, which involves carrying out the operation directly in conjunction with the first visit, has been shown to reduce cost significantly. ${ }^{17}$ One study investigating direct listing for oral surgery procedures found this to be an effective approach. ${ }^{16}$ Sufficient information is mandatory for allowing appropriate triage and for the assessment of clinical need and urgency., ${ }^{2,18}$ Busy general practitioners prioritize chair time over administration, 
and there has to be benefits to both the referrer and the receiving specialist if a new referral system is to be successful. By raising the bar on submissions, the patients' and society's resources can be better allocated and utilized. One method imposed in the United Kingdom involved the introduction of referring guidelines such as the NICE guidelines. These were introduced to avoid unnecessary referrals for elective removal of wisdom teeth. ${ }^{19}$ Some published clinical audits have shown improvement in general dentist referrals following the introduction of third molar guidelines. ${ }^{20}$

Gender inequality is a relevant and interesting issue in many aspects of society. Women are progressively more represented in the younger cohorts of the dental workforce. ${ }^{21}$ One recent observational study in USA discovered that female physicians were less frequently associated with premature death of elderly patients. ${ }^{22}$ Nevertheless, female physicians and dentists in Sweden also take home less pay compared to male collegues. ${ }^{23}$ There might be a slight tendency for female dentists to produce more detailed referrals according to our analysis. The most significant differences between the genders were observed in the medical history and in the radiograph categories. The authors have no scientific explanation for these differences. It can be speculated that traditional gender roles or biological causes lead women to have a greater interest in particular aspects of health care. Although women overall had a slight edge over male colleagues, there are too many confounding factors in this study to draw any significant conclusions.

This study did not distinguish referrers on age, demographics, or the university they graduated from. In general, there were no major significant differences in terms of quality of referrals between private dental clinics and PDH clinics. PDH clinics fared better when it came to including radiographs. PDH clinics sent more referrals than private dental health care providers, which could have been influenced by differing financial incentives or demographics of their patients. Although the differences were small in this paper, economic incentives can probably explain some of these findings. It is perhaps encouraging to know that dentists' performance was not strongly linked to their employment status in this study.

For future research, another aspect not discussed in this paper is the quality of referrals versus the quality of referral replies. One paper we identified showed that better quality of general practitioners' referral letters led to only marginally improved referral replies by specialists. ${ }^{24}$ It would be interesting to investigate if improved referrals to our oral surgery department improved our correspondence to our referrers. Moreover, referral letters should not be encouraged to be very lengthy. It is the authors' opinion that the important information needs to be correctly summarized and presented clearly. Electronic referral systems could help to achieve this through checkboxes and dropdown menus.

We suggest that future electronic referrals systems should only allow for submission once mandatory information has been considered. This is similar to previous audits that we have identified which have suggested using feedback mechanisms, referring templates, or electronic referral templates to improve standards. ${ }^{3,5,6,25}$ We welcome the development of guidelines for minimum requirements of referral letters in Sweden.

\section{Summary}

Finally, this retrospective study of referral letters confirms, in accordance with previous studies, that quality of oral surgery referral letters leaves a lot of room for improvement. Submission should only be allowed once mandatory information has been addressed in the referral. This should be kept in mind as new health care software is designed in the future. We suggest improving submission of referrals with the aim of improving the quality, achieving better time management, and reducing suffering.

\section{Disclosure}

The authors report no conflicts of interest in this work.

\section{References}

1. Burke FJT, Freeman R. Referrals. Dental Update. 2007;34:338-339.

2. Lang M, Selvadurai T, Zakrzewska JM. Referrals to a facial pain service. Br Dent J. 2016;220(7):345-348.

3. Djemal S, Chia M, Ubaya-Narayange T. Quality improvement of referrals to a department of restorative dentistry following the use of a referral proforma by referring dental practitioners. Br Dent J. 2004;197(2):85-88; discussion 82; quiz 100-101.

4. Rosenquist B. Många brister i remisser till käkkirurgisk klinik [Many shortcomings in referrals received at an oral and maxillofacial clinic] Swedish Dental J. 2006;98(7):60.

5. Moloney J, Stassen LF. An audit of the quality of referral letters received by the department of oral and maxillofacial surgery, Dublin dental school and hospital. J Ir Dent Assoc. 2010;56(5):221-223.

6. Dentith GE, Wilson KE, Dorman M, Girdler NM. An audit of patient referrals to the sedation department of Newcastle dental hospital. Prim Dent Care. 2010;17(2):85-91.

7. Izadi M, Gill DS, Naini FB. A study to assess the quality of information in referral letters to the orthodontic department at Kingston hospital, Surrey. Prim Dent Care. 2010;17(2):73-77.

8. Harris L, Hodgson E, Hill V, Walker T, Felstead A. The appropriateness of referrals made by general dental practitioners to the oral and maxillofacial surgery department for routine exodontia. Int J Oral Maxillofac Surg. 2017;44:e304.

9. Liedholm R, Knutsson K, Norlund A. Economic aspects of mandibular third molar surgery. Acta Odontol Scand. 2010;68(1):43-48.

10. Liedholm R. Mandibular third molar removal: Patient preferences, assessments of oral surgeons and patient flows. Swed Dent J Suppl. 2005; 175:1-61. 
11. Patel M, Khan AQ, Thiruchelvam J. Importance of quality in referral. Letters sent for potentially malignant oral, head and neck lesions. Dent Update. 2011;38:192-198.

12. American Dental Association. General guidelines for referring dental patients to specialists and other settings for care. Gen Dent. 2007;55(2):87-89.

13. Swedish National Board of Health and Welfare. SOSFS 2004:11 Statues; 2004. Available from: https://www.socialstyrelsen.se/Lists/ Artikelkatalog/Attachments/10255/2004-10-11_2004_11.pdf. Accessed March 20, 2017.

14. Liedholm R, Henricsson V, Lysell L, et al. Patient flows in the care process of mandibular third molar surgery. Swed Dent J. 2005;29(3):97-104.

15. Gruber E, Messahel A. The availability of imaging with new patient referrals. Int J Oral Maxillofacial Surg. 2013;42(10):1256.

16. Renton T, McGurk M. Direct referral day case oral surgery for dental practitioners: A pilot investigation. Br Dent J. 1999;186(7):334-337.

17. Shah C, Griffiths M, Moralee S. Direct listing for adult tonsillectomy. $J$ R Coll Surg Edinb. 1997;42(1):45-46.

18. Zakrzewska JM. Referral letters--how to improve them. Br Dent J. 1995;178(5):180-182.

19. The National Institute for Health and Clinical Excellence (NICE). NICE technology appraisal guidance number 1 . Guidance on the extraction of wisdom teeth; 2000 [updated March 16, 2015; cited March 20, 2017]. Available from: https://www.nice.org.uk/guidance/ta1. Accessed March 20, 2017.
20. Worrall SF. An audit of general dental practitioners' referral practice following the distribution of third molar guidelines. Ann R Coll Surg Engl. 2001;83(1):61-64.

21. Kvinnornas dominans ökar [Female dominance on the rise]. Swedish Dental J. 2014;7(106):6.

22. Tsugawa Y, Jena A, Figueroa JF, Orav EJ, Blumenthal DM, Jha AK. Comparison of hospital mortality and readmission rates for medicare patients treated by male vs female physicians. JAMA Intern Med. 2017;177(2):206-213.

23. Andrén T, Pokarzhevskaya G, Swedish Confederation of Professional Associations (SACO). Förklarat och oförklarat mellan kvinnor och män. löneskillnader bland sacoförbundens medlemmar [Explained and unexplained between women and men. Salary differences amongst SACO union members]; 2017. Available from: http:/www.saco.se/ globalassets/saco/dokument/rapporter/2017-forklarat-och-oforklarat. pdf. Accessed March 20, 2017.

24. Grol R, Rooijackers-Lemmers N, van Kaathoven L, Wollersheim $\mathrm{H}$, Mokkink H. Communication at the interface: Do better referral letters produce better consultant replies? Br J Gen Pract. 2003;53(488):217-219.

25. Shaffie $\mathrm{N}$, Cheng L. Improving the quality of oral surgery referrals. $\mathrm{Br}$ Dent J. 2012;213(8):411-413.
Clinical, Cosmetic and Investigational Dentistry

\section{Publish your work in this journal}

Clinical, Cosmetic and Investigational Dentistry is an international, peer-reviewed, open access, online journal focusing on the latest clinical and experimental research in dentistry with specific emphasis on cosmetic interventions. Innovative developments in dental materials, techniques and devices that improve outcomes and patient satisfac-
Dovepress

tion and preference will be highlighted. The manuscript management system is completely online and includes a very quick and fair peerreview system, which is all easy to use. Visit http://www.dovepress. com/testimonials.php to read real quotes from published authors. 